\title{
O CLÁSSICO E O CONTEMPORÂNEO, HOJE, EM ALGUMA POESIA PORTUGUESA CONTEMPORÂNEA
}

\author{
THE CLASSIC AND THE CONTEMPORARY, \\ TODAY, IN SOME PORTUGUESE POETRY
}

Paula Cristina Costa ${ }^{*}$

\section{RESUMO}

A partir do ensaio de Giorgio Agamben, «O que é o Contemporâneo?» (in Nudez, Relógio d’Água, 2010), pretende-se reflectir sobre o Contemporâneo, em geral, e sobre a literatura portuguesa contemporânea, em particular. O Contemporâneo é entendido não como uma categoria histórica ou cronológica, mas sim como uma categoria a-histórica, como o texto que se consegue manter actual ao longo dos tempos. Para exemplificar esta ideia, algumas poéticas de poetas portugueses são tomadas em consideração de modo a estabelecer-se o diálogo entre o clássico e o contemporâneo: Camões, Cesário Verde, Herberto Helder, Ruy Belo, Nuno Júdice, Manuel de Freitas e Gonçalo M. Tavares são alguns desses poetas escolhidos.

PALAVRAS- CHAVE: Contemporâneo; Moderno; Clássico; Poesia Portuguesa

\section{ABSTRACT}

Starting from the Giorgio Agamben essay, "O que é o Contemporâneo?” (in Nudez, Relógio d'Água, 2010), we intend to reflect on the contemporary, in general, and on contemporary Portuguese literature in particular. The Contemporary is understood not as a historical or chronological category, but rather as an unhistorical category, as text that can maintain itself current over time. To illustrate this idea, some poetics of Portuguese poets are taken into account in order to establish the dialogue between the classic and the contemporary: Camões, Cesário Verde, Herbert Helder, Ruy Belo, Nuno Júdice, Manuel de Freitas and Gonçalo M. Tavares are some of the chosen poets.

KEYWORDS: Contemporary; Modern; Classic; Portuguese Poetry 
Falarmos de poesia portuguesa contemporânea, leva-nos, num primeiro momento, a questionarmos o que entendemos, hoje, por poesia contemporânea, ou mesmo por contemporâneo. Não sendo aqui o momento de nos alongarmos sobre esta reflexão teórica em torno do contemporâneo, citaria aqui apenas o ensaio de Giorgio Agamben, «O que é o contemporâneo?», in Nudez (2010) como ponto de partida para esta questão. Para Agamben, o contemporâneo não é uma categoria histórica ou cronológica, mas uma categoria intempestiva, intemporal. Contemporâneo será o autor ou texto que se consegue manter actual, contemporâneo de todos os tempos e que por isso não se deve confundir com o autor mais jovem, mais recente ou pertencente a uma geração do presente.

Muito antes de Agamben, já Ortega Y Gasset tinha alertado para esta mesma questão, dizendo que não se deve confundir contemporâneo com coetâneo: nem todos os autores que coincidem connosco num mesmo tempo são nossos contemporâneos. («La ideia de generacion», in Revista Occidente, 1956). Poderão ser ou não. O contemporâneo terá então mais a ver com afinidades electivas entre textos e autores do que propriamente com datas cronológicas. Ser contemporâneo é um predicado psicológico e existencial, ético e estético, mais do que temporal ou histórico; é um tempo íntimo, de partilha de textos e autores, mais do que um tempo histórico. Para que dois textos possam ser contemporâneos, não têm que ter a mesma data ou pertencer à mesma geração; pelo contrário, por vezes, quanto mais distantes no tempo, mais afinidades os podem aproximar. Como afirmou Alain Badiou ("L`âge des poètes", 1992), a idade dos poetas não é uma idade histórica, mas uma idade filosófica.

Partindo desta ideia, falar de poesia portuguesa contemporânea, não é obrigatoriamente falar da poesia do século XX portuguesa, ou mais precisamente falar dos poetas que publicaram a partir da segunda década do século XX. Poderá sê-lo ou não. Porque facilmente poderemos provar que poetas como Cesário Verde ou Fernando Pessoa, ou ainda numa linha mais radical, Camões, são poetas contemporâneos, pela actualidade das suas poéticas, pela ressonância poética que continuam a ter em sucessivas gerações de poetas portugueses, em todo o século XX e já mesmo de década e meia do século XXI.

É conhecido o diálogo entre muitos dos poetas cronologicamente pertencentes à "literatura portuguesa contemporânea", e muitos destes poetas citados. Sophia, por exemplo, no seu diálogo com Pessoa. Mas também no diálogo com Camões e Cesário, para além de Homero e de outros clássicos da literatura. O diálogo entre Ruy Belo e Pessoa. Por sua vez, Pessoa e o diálogo com Camões e Cesário. Jorge de Sena e o diálogo com Camões; Nuno Júdice e Camões, Cesário e Pessoa. Herberto Helder, Gastão Cruz, Fiama, Vasco Graça Moura, Ana Luísa Amaral, Manuel de Freitas, António Carlos Cortez, Gonçalo M. Tavares, entre muitos outros, e o diálogo ainda continuado com Camões. 
De facto, o diálogo entre o clássico e o contemporâneo, ou mesmo as fronteiras entre clássico e contemporâneo são aqui muito ténues. Quem será mais contemporâneo: Sophia ou Pessoa? Herberto ou Camões? Tavares ou Camões? Num primeiro momento, à luz da ideia mais imediata de contemporâneo, não temos dúvidas. Sophia, Herberto e Tavares são poetas incontornavelmente contemporâneos, porque publicaram a partir das décadas de 40 do século XX, ou mesmo da primeira década do século XXI, no caso de Tavares. Mas se partirmos do pressuposto de Agamben de que o contemporâneo não se mede por uma cronologia mas por uma actualidade, então, teríamos provavelmente de repensar a questão noutros termos.

Ser contemporâneo não é uma questão geracional, porque sabemos o quanto podem ser diversificados poetas pertencentes a uma mesma geração e o quanto podem não se reconhecer como contemporâneos uns dos outros. Pessoa e Sá-Carneiro foram contemporâneos, da mesma geração de Orpheu, de Cortes Rodrigues ou de Luis de Montalvor e de Ronald de Carvalho e isso por si só não é garantia de afinidades entre as suas poéticas, ou de falarem uma mesma linguagem poética. Adolfo Casais Monteiro foi companheiro da Presença de João Gaspar Simões e é conhecida a distância poética, íntima ou como lhe quisermos chamar, que os separa. E assim por aí fora. Ruy Belo, no seu primeiro livro, «Aquele Grande Rio Eufrates», em «Epígrafe para a nossa solidão», adverte-nos disso: «Cruzámos nossos olhos em alguma esquina/demos civicamente os bons dias/chamar-nos-ão vais ver contemporâneos» (in Todos os Poemas, 2000, p. 57). Esta epígrafe de Ruy Belo parodia a acepção historicista de contemporâneo. Também para este poeta, o contemporâneo não é o coetâneo que se cruza ou coincide connosco numa esquina, mas é algo mais complexo. Tal como Derrida disse, numa entrevista dada a um jornal, «podemos ser contemporâneos de uma geração passada ou a vir.».

Então, o que é que faz de um poeta, ou qualquer escritor/artista, um poeta contemporâneo? E o que podemos entender, hoje, por contemporâneo? Pergunta difícil desde sempre de responder. A mesma dificuldade que já Baudelaire teve ao tentar definir o que era a modernidade; ou que tiveram sucessivas épocas, ao tentarem definir o que seria o moderno. Lembremos que para Baudelaire, a modernidade seria esse instante eterno, em que o transitório e o eterno se fundiriam. Retirar do efémero aquilo que ele tem de imutável. Esse seria o perfil do pintor moderno, da arte moderna. Mutatis mutandi, poderíamos dizer o mesmo do contemporâneo: será contemporâneo aquele texto ou autor que se consegue eternizar, ultrapassar as barreiras da data em que viveu ou publicou, e projectar-se num sem tempo, num presente fora do tempo do aqui e do agora.

Não deixa de ser curiosa a necessidade sentida por alguns poetas do século XX/XXI portugueses, para nos restringirmos apenas às balizas temporais que importam tomar em consideração hoje e aqui, de recorrerem aos clássicos para sedimentarem a sua modernidade, ou para se projectarem nessa intemporalidade que todos os autores almejam. Tome-se o 
exemplo dum dos nossos autores mais recentes, Gonçalo M. Tavares, e do seu livro Viagem à Índia (2010). Este livro é um bom exemplo dessa procura duma poética intemporal, que redescobre e recria os clássicos da literatura, neste caso, não só portuguesa mas também mundial. O que Tavares aqui faz é reconstruir a estrutura e a temática dos «Lusíadas» de Camões, mitigada com a modernidade homérica de «Ulisses» de Joyce, para nos falar da melancolia do herói pós-moderno, da falência das epopeias e dos heróis clássicos, das sociedades da decadência do consumismo e dos valores morais. Nesta contra ou anti epopeia é bem visível essa necessidade de revisitar os clássicos e de os trazer para o presente nosso contemporâneo, num confronto crítico de tempos e de valores. Mas é também visível uma arte poética deste autor do Bairro que se desenvolve na procura de um diálogo permanente com textos e autores muito antigos. Veja-se um dos últimos livros agora publicado, «Os velhos também querem viver», escrito a partir de «Alceste» de Eurípedes, onde Tavares reincide nesse diálogo intertextual com o muito antigo, com o clássico que se deseja contemporâneo, para que o mais contemporâneo possa também advir clássico.

É interessante constatarmos que alguns dos nossos melhores poetas contemporâneos querem e sabem manter uma inteligente relação com os clássicos. Retomo alguns dos exemplos já aqui referidos, para além do de Gonçalo M. Tavares: Sophia, Herberto, Ruy Belo, Jorge de Sena, Nuno Júdice, para não me alongar mais. Trata-se do exemplo de poetas que se nutrem ou de mitos clássicos para os renovarem, ou de autores clássicos que resgatam para os tempos actuais. Certamente que isto não será suficiente, por si só, para os tornar bons poetas. Mas a verdade é que ao inscreverem-se nesta linhagem da tradição, do muito antigo, conseguem falar uma linguagem mais universal, um fora do tempo, uma intempestividade que poderá ajudar a resgatar essa modernidade baudelairiana, ao conseguir retirar "da moda aquilo que ela pode conter de poético no histórico, de extrair o eterno do transitório". (2006, p. 21).

Num tempo em que é cada vez mais difícil ser-se absolutamente original, não ter consciência e medo das influências, não as assumir como parte integrante da sua poética, muitos poetas, sobretudo a partir de Pessoa, optam por assumir estas presenças de modo explícito, para as renovar ou mesmo parodiar. Este sintoma já foi há muito diagnosticado como característica predominante do pós-modernismo na literatura. Na poesia portuguesa mais recente, muitos dos nossos poetas partem dessa dificuldade de serem «génios solitários» e enfrentam um diálogo corpo a corpo com os seus pares, fora do tempo. Para além do exemplo que já referi de Gonçalo M. Tavares, também muitos outros poetas, como Manuel de Freitas, por exemplo, regressam muitas vezes aos clássicos para aí se reencontrarem com a sua geração de afinidades filosóficas, éticas ou estéticas, e não propriamente, com a sua geração histórica.

Neste caso específico de Manuel de Freitas, Luís Maffei já estudou longamente a presença de Camões na sua obra. («Ciranda da poesia», 
2014). Não deixa de ser curioso que um dos poetas sem qualidades mais importante, mantenha a presença tão viva de Camões na sua poesia. Aliás, como o próprio Maffei, agora enquanto poeta, num dos seus mais recentes livros de poesia publicado, «Signos de Camões» (2013), também o faz. Esta revisitação permanente dos clássicos por alguns dos nossos poetas mais recentes faz-nos também repensar o que significa, hoje, ser contemporâneo. Mais do que a data dos textos publicados, ou a idade dos poetas, os critérios para a definição de literatura contemporânea deveriam ser repensados à luz de características menos históricas ou temporais e mais estéticas. Nem sempre o poeta mais jovem é o mais contemporâneo. Nem o mais antigo, o mais clássico ou démodé.

Leia-se o início e o fim do poema «Cronofobia» (2002), de Manuel de Freitas: «Sou contemporâneo de Villon/ e escrevo às vezes a Montaigne». (...) «e um galgo aproxima-se devagar/ da mão que nunca lerá José Saramago.» (p.24)

Como espero que já se tenha tornado bem claro, não estou aqui a ter a pretensão de responder a nenhuma pergunta e muito menos a tentar dar uma resposta à pergunta, o que é o contemporâneo, ou o que é hoje o contemporâneo. Estou apenas a por em causa ou a repensar a própria ideia de literatura portuguesa, ou qualquer outra, que se diga contemporânea. Cada vez assistimos mais à tendência de publicações de antologias de poetas reunidos por séculos ou mesmo por décadas. A agrupamentos em torno de revistas literárias. Lembremos alguns exemplos a partir da década de 50: «A Árvore» (1951-53); Po-Ex (1961); muitos anos depois, o reavivar desta ideia de geração, mesmo que pela negativa, no sentido de uma anti-geração, nos «Poetas sem qualidades» (2002) e ainda, mais recentemente, nos poetas em torno da revista «Criatura» (2008). As mesmas questões se colocam, aquando da Geração de Orpheu, da Presença, dos Surrealistas, ou de muitas outras gerações ou grupos: apesar de serem poetas que à partida, partilham de um programa poético comum, bem organizado, em torno de uma revista, muitas vezes liderada por um ou dois nomes bastante importantes de proa, serão, realmente, estes poetas, todos eles contemporâneos entre si? E todos eles, realmente, poetas contemporâneos?

Parece-me que não. Por isso penso que é necessário ser-se cauteloso quando se fala de literatura contemporânea, seja de que nacionalidade for. Ela nem sempre é a mais recente, a dos últimos 50 anos ou da última década. Talvez seja muito mais do que isso. Ou então teremos de distinguir $o$ que consideramos o nosso contemporâneo, os nossos poetas contemporâneos, ou seja ofugitivo, sem o eterno, (de novo Baudelaire) do contemporâneo, tout court, dos poetas contemporâneos, ou seja o eterno para além do fugitivo. E aí, cada um é livre de reconhecer ou de inventar os seus contemporâneos.

Creio que alguma da nossa poesia mais recente sabe e gosta de inventar os seus contemporâneos. Para além dos que ainda conseguem ser, se já não filhos, talvez netos de Álvaro de Campos, temos os «filhos de Her- 
berto Helder», os «filhos de Ruy Belo», os «filhos de Joaquim Manuel Magalhães», os «filhos de Adília Lopes» e por aí em diante... Mas a verdade, é que continuamos a ter poetas como Camões e Cesário Verde, por exemplo, muito presentes na nossa poesia mais recente. Talvez seja um sintoma de que a nossa poesia mais jovem sabe que o absolument moderne (de Rimbaud) convive bem com a «massa em movimento» que são os clássicos e nela procura extrair o eterno do transitório.

\section{REFERÊNCIAS BIBLIOGRÁFICAS}

AGAMBEN, Giorgio. “O que é o contemporâneo?” (2006/7), in Nudez. Lisboa: Relógio d’Água, 2010.

BADIOU, Alan. "Lâge des Poètes", in RANCIÈRE, Jacques (dir.). La politique des poètes: pourquoi des poères en temps de détresse?. Paris: Bibliothéque du Collége Internacional de Philosophie, 1992.

BAUDELAIRE, Charles. O Pintor da Vida Moderna, Lisboa: Vega, 2006.

BELO, Ruy. Todos os Poemas. Lisboa: Assírio \& Alvim, 2000.

FREITAS, Manuel. [SIC]. Lisboa: Assírio \& Alvim, 2002.

. Poetas sem qualidades. Lisboa: Averno, 2002.

MAFFEI, Luis (est.introd., sel.). Manuel de Freitas. Rio de Janeiro: EdUERJ, 2014. [Col. Ciranda da Poesia]

. Signos de Camões. Rio de Janeiro: Oficina Raquel, 2013.

ORTEGA Y GASSET. «La ideia de generacion», in Revista Occidente, 1956.

TAVARES, Gonçalo M. Viagem à Índia. Lisboa: Leya, 2010.

Recebido para publicação em 31/07/2015

Aprovado em 28/09/2015

\section{NOTAS}

* Paula Cristina Costa, Professora Auxiliar com Agregação, do Departamento de Estudos Portugueses da FCSH da Universidade Nova de Lisboa. Universidade onde realizou a sua Licenciatura, Mestrado e Doutoramento. Áreas Científicas: Literatura Portuguesa Contemporânea e Literatura Comparada. 